\title{
Erratum to: Enhanced Stability of Ramipril in Nanoemulsion Containing Cremophor-EL: A Technical Note
}

Sheikh Shafiq ${ }^{1,3}$ and Faiyaz Shakeel ${ }^{2}$

Published online 1 February 2011

\section{Erratum to: AAPS PharmSciTech \\ DOI 10.1208/s12249-008-9151-8}

Roop K Khar; Department of Pharmaceutics, Faculty of Pharmacy, Jamia Hamdard, Hamdard Nagar, New Delhi was erroneously omitted as a co-author of the original article.

The online version of the original article can be found at http://dx.doi. org/10.1208/s12249-008-9151-8

${ }^{1}$ New Drug Delivery System (NDDS), Zydus Cadila Healthcare Ltd, Ahemdabad, India.

${ }^{2}$ Department of Pharmaceutics, Faculty of Pharmacy, Al-Arab Medical Sciences University, Benghazi, Libya.

${ }^{3}$ To whom correspondence should be addressed. (e-mail: shafiq_ sheikh@fastmail.fm) 